\title{
Therapeutic outcomes of transsphenoidal surgery in pediatric patients with craniopharyngiomas: a single-center study
}

\author{
Shozo Yamada, MD, PhD, ${ }^{1,5}$ Noriaki Fukuhara, MD, ${ }^{1}$ Mitsuo Yamaguchi-Okada, MD, PhD, ${ }^{1}$ \\ Hiroshi Nishioka, MD, PhD, 1,5 Akira Takeshita, MD, PhD,, 2,5 Yasuhiro Takeuchi, MD, PhD, 2,5 \\ Naoko Inoshita, MD, PhD,, 5 and Junko Ito, MD 3
}

Departments of ${ }^{1}$ Hypothalamic and Pituitary Surgery, ${ }^{2}$ Endocrinology, ${ }^{3}$ Pediatrics, and ${ }^{4}$ Pathology, Toranomon Hospital; and ${ }^{5}$ Okinaka Memorial Institute for Medical Research, Tokyo, Japan

OBJECTIVE The aim of this study was to analyze the outcomes of transsphenoidal surgery (TSS) in a single-center clinical series of pediatric craniopharyngioma patients treated with gross-total resection (GTR).

METHODS The authors retrospectively reviewed the surgical outcomes for 65 consecutive patients with childhood craniopharyngiomas ( 28 girls and 37 boys, mean age 9.6 years) treated with TSS (45 primary and 20 repeat surgeries) between 1990 and 2015. Tumors were classified as subdiaphragmatic or supradiaphragmatic. Demographic and clinical characteristics, including extent of resection, complications, incidence of recurrence, pre- and postoperative visual disturbance, pituitary function, and incidence of diabetes insipidus (DI), as well as new-onset obesity, were analyzed and compared between the primary surgery and repeat surgery groups.

RESULTS Of the 45 patients in the primary surgery group, 26 (58\%) had subdiaphragmatic tumors and 19 had supradiaphragmatic tumors. Of the 20 patients in the repeat surgery group, $9(45 \%)$ had subdiaphragmatic tumors and 11 had supradiaphragmatic tumors. The only statistically significant difference between the 2 surgical groups was in tumor size; tumors were larger (mean maximum diameter $30 \mathrm{~mm}$ ) in the primary surgery group than in the repeat surgery group (25 $\mathrm{mm})(p=0.008)$. GTR was accomplished in $59(91 \%)$ of the 65 cases; the GTR rate was higher in the primary surgery group than in the repeat surgery group ( $98 \%$ vs $75 \%, p=0.009$ ). Among the patients who underwent $\mathrm{GTR}, 12 \%$ experienced tumor recurrence, with a median follow-up of 7.8 years, and recurrence tended to occur less frequently in primary than in repeat surgery patients ( $7 \%$ vs $27 \%, p=0.06)$. Of the 45 primary surgery patients, $80 \%$ had deteriorated pituitary function and $83 \%$ developed DI, whereas $100 \%$ of the repeat surgery patients developed these conditions. Among patients with preoperative visual disturbance, vision improved in $62 \%$ but worsened in $11 \%$. Visual improvement was more frequent in primary than in repeat surgery patients $(71 \%$ vs $47 \%, p<0.001)$, whereas visual deterioration was less frequent following primary surgery than repeat surgery ( $4 \%$ vs $24 \%, p=0.04)$. Among the 57 patients without preoperative obesity, new-onset postoperative obesity was found in $9 \%$ of primary surgery patients and $21 \%$ of repeat surgery patients $(p=0.34)$ despite aggressive resection, suggesting that hypothalamic dysfunction was rarely associated with GTR by TSS in this series. However, obesity was found in $25 \%$ of the repeat surgery patients preoperatively due to prior transcranial surgery. Although there were no perioperative deaths, there were complications in 12 cases (18\%) (6 cases of CSF leaks, 3 cases of meningitis, 2 cases of transient memory disturbance, and 1 case of hydrocephalus). Postoperative CSF leakage appeared to be more common in repeat than in primary surgery patients $(20 \% \mathrm{vs} 4.4 \%, p=0.2)$.

CONCLUSIONS The results of TSS for pediatric craniopharyngioma in this case series suggest that GTR should be the goal for the first surgical attempt. GTR should be achievable without serious complications, although most patients require postoperative hormonal replacement. When GTR is not possible or tumor recurrence occurs after GTR, radiosurgery is recommended to prevent tumor regrowth or progression.

https://thejns.org/doi/abs/10.3171/2017.10.PEDS17254

KEYWORDS endoscopic endonasal approach; extended transsphenoidal approach; hypothalamic obesity; pediatric craniopharyngioma; skull base surgery; transsphenoidal surgery; pituitary surgery

ABBREVIATIONS BMI = body mass index; DI = diabetes insipidus; exTSS = extended TSS; GTR = gross-total resection; IQR = interquartile range; QoL = quality of life; $\mathrm{SD}=$ standard deviation; $\mathrm{STR}=$ subtotal resection; TCS = transcranial surgery; TSS = transsphenoidal surgery; VP = ventriculoperitoneal.

ACCOMPANYING EDITORIAL See pp 545-548. DOI: 10.3171/2017.11.PEDS17568.

SUBMITTED May 13, 2017. ACCEPTED October 10, 2017.

INCLUDE WHEN CITING Published online March 30, 2018; DOI: 10.3171/2017.10.PEDS17254. 


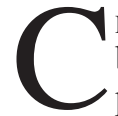
HILDHOOD-ONSET craniopharyngiomas are rare embryonic malformations arising from the sellar and parasellar area of the brain. Despite the low histological grade (WHO grade I) and high survival rates (90\%-95\%) associated with craniopharyngioma, quality of life $(\mathrm{QoL})$ is frequently impaired in long-term survivors due to neuroendocrine sequelae caused by the anatomical proximity of the tumor to the optic nerve and hypothalamic-pituitary axes., ${ }^{9,58,63}$ Moreover, craniopharyngioma causes high mortality, especially in patients with childhood-onset tumors, and increased death due to cerebrovascular disease. ${ }^{49}$ Therefore, childhood craniopharyngioma should be recognized as a chronic disease that requires constant monitoring of the clinical and QoL consequences, and the treatment should be tailored to individual patients. To prevent severe sequelae, Müller et al. have advised against complete tumor resection of tumors with close proximity to optic and/or hypothalamic structures; ${ }^{44}$ however, this recommendation was mainly based on surgical outcomes of transcranial approaches. In contrast, transsphenoidal surgery (TSS), including extended TSS (exTSS), offers improved exposure and surgical access of the suprasellar and retrosellar region, allowing for more extensive tumor resection and providing an excellent midline view of the ventral floor of the third ventricle without retraction of vital structures. ${ }^{64}$ Although there is increasing acceptance of transsphenoidal resection in adults, its use is less commonly reported in the pediatric population. ${ }^{6,28,37,55,61}$ Moreover, the majority of previously reported pediatric craniopharyngioma series include only a small number of TSS-treated patients. Here, we report the outcomes of TSS in a consecutive series of 65 pediatric craniopharyngioma patients operated on by a single surgeon (S.Y.), at a single institution, with the goal of gross-total resection (GTR). This study was approved by the ethics committee of Toranomon Hospital in Tokyo.

\section{Methods \\ Patient Population}

Between 1990 and 2015, 264 craniopharyngioma patients underwent TSS at Toranomon Hospital in Tokyo. Of those patients, $70(26.5 \%)$ underwent TSS at less than 18 years of age: 12 patients were 5 years of age or younger, 24 were older than 5 years and younger than 10 years, and 34 were 10 years of age or older. Among these 70 pediatric patients, 54 underwent TSS between 2006 and 2015, whereas 4 underwent transcranial surgery (TCS) for their pediatric craniopharyngiomas during the same period. Thus, approximately $93 \%$ of the pediatric craniopharyngioma patients (54 of 58) were surgically treated via a transsphenoidal approach in the past 10 years at Toranomon Hospital. In this study, we included 65 of these 70 pediatric craniopharyngioma patients, all of whom were operated on by the same surgeon (S.Y.), whereas the remaining 5 patients were excluded because other doctors performed their operations.

\section{Endocrine Examination}

All patients were admitted to the pediatric ward and evaluated by our pediatric endocrinologists. Each patient underwent various biochemical examinations to assess their anterior and posterior pituitary function. Provocation tests were performed preoperatively and postoperatively with growth hormone-releasing hormone or growth hormone-releasing peptide-2, corticotropin-releasing hormone, thyrotropin-releasing hormone, and luteinizing hormone-releasing hormone. Serum growth hormone, prolactin, thyroid-stimulating hormone, luteinizing hormone, follicle-stimulating hormone, adrenocorticotropic hormone, and cortisol levels were measured in blood samples drawn at $0,15,30,45,60,90$, and 120 minutes and assessed by pediatric endocrinologists.

\section{Neuroimaging}

Preoperative CT and MRI studies were used to determine tumor location, size, cystic change, calcification, and sellar enlargement. Postoperative MRI was performed after 10 days, at 6 and 12 months, and then at yearly intervals. Follow-up periods after the final surgery ranged from 15 to 307 months (mean 7.8 years). Identification of tumor calcification was assessed using bone-targeting CT scans. Craniopharyngiomas were divided into 2 types based on their location and relationship with the diaphragm or sella turcica as follows: 1) subdiaphragmatic type, arising from the pituitary fossa with an intrasellar (sellar subtype) or a suprasellar (suprasellar subtype) extension related to a large sellar entrance, or 2) supradiaphragmatic type, located in the suprasellar area, without sellar involvement, with the diaphragm and pituitary gland being located underneath the tumor. Tumors were divided into the following 3 size groups based on their maximum diameter as assessed by MRI: small, $<2 \mathrm{~cm}$; moderate, $2-4 \mathrm{~cm}$; and large, $>4$ $\mathrm{cm}$. In addition, the preoperative MR images were classified according to the presurgical score of hypothalamic involvement proposed by Puget et al. as follows: grade 0, no hypothalamic involvement; grade 1, tumor abutting or displacing the hypothalamus; and grade 2 , hypothalamic involvement (the hypothalamus is no longer identifiable). ${ }^{53}$

\section{Ophthalmological Evaluation}

All patients, except the youngest (age $<4$ years in this series), in whom testing was difficult, underwent an ophthalmological examination for visual acuity and perimetry. These examinations were performed before and 2 weeks after surgery; additional assessments were performed later in some cases, determined on a case-by-case basis.

\section{Assessment of Tumor Removal}

Tumor removal was assessed based on the intraoperative surgeon's findings and the results of the postoperative contrast-enhanced MRI study performed between 3 and 6 months after surgery. Tumor removal was classified as GTR when no residual tumor was found upon intraoperative assessment and postoperative MRI, subtotal resection (STR) when more than $75 \%$ of the tumor (but not all) was excised, or partial removal when less than $75 \%$ of the tumor was excised.

\section{Surgical Procedure}

The surgery was performed according to previously 
described techniques. ${ }^{61}$ Briefly, in 1998, we adopted the extended transplanum sphenoidale approach, referred to as exTSS, as an alternative method to reach supradiaphragmatic suprasellar tumors. Prior to 1998, 4 of the 65 patients in this case series underwent conventional TSS; of these 4 patients, 2 had sellar tumors with no or only minimal suprasellar extension and 2 had sellar tumors with marked suprasellar extensions. From 2000 until 2012, TSS was performed with the help of endoscopy (endoscopeassisted microscopic TSS), and after 2012, we switched to a purely endoscopic TSS method. The microscopic TSS was performed using the less-invasive, modified sublabial approach in younger children, usually less than 10 years of age, or the endonasal approach in older children. ${ }^{52}$ In the endonasal approach, the contralateral nostril was chosen when the tumor projected more to one side. Since 2012, using purely endoscopic TSS, we have used the 2-nostril endonasal approach regardless of patient age. In the most recent 19 cases, purely endoscopic TSS was performed by a single surgeon using an endoscope-holding system (UniARM, Mitaka Kohki Co., Ltd.) (Video 1).

VIDEO 1. Video clip showing purely endoscopic exTSS for the treatment of a supradiaphragmatic craniopharyngioma in which hypothalamic involvement was suspected based on preoperative MRI. Copyright Shozo Yamada. Published with permission. Click here to view.

During surgery, an ultrasonic aspirator (SONOPET, Stryker), an intraoperative image guidance system, and a micro-Doppler ultrasonography system were used for safe and effective removal of the craniopharyngiomas.

For the reconstruction step of the procedure, we used the following techniques: 1) the intrasellar and sphenoidal sinus-packing method, which involved packing fat tissue with fibrin glue into the enlarged sella and sphenoidal sinus (used before 2000); 2) the dural fascia graft method, in which the large dural defect resulting from surgery was patched with fascia harvested from the right quadriceps and sutured side by side with 6-0 nylon, in a watertight manner (usually 15-20 stitches), with or without bony reconstruction of the sellar floor, followed by packing of fibrin glue or fat tissue into the remaining sphenoidal sinus; ${ }^{61}$ or 3 ) the simple dural fascia graft with vascularized nasoseptal flap method, in which the large dural defect was similarly patched with fascia and inlay sutured with less than 8 stitches, with or without bony reconstruction of the sellar floor, and then completely covered with the nasoseptal flap (used since 2012). ${ }^{25}$ The nasoseptal flap was raised, according to the Hadad-Bassagasteguy method, when approaching the sphenoidal sinus and kept in the choana during surgery. ${ }^{22}$

\section{Pathological Analysis}

The histological characteristics of each tumor were determined by routine light microscopic evaluation. The histological diagnosis was reconfirmed retrospectively in all 65 cases by one of the authors (N.I.).

\section{Obesity}

The body mass index (BMI) is widely used in adults but not in children. ${ }^{9}$ In this study, we calculated the BMI standard deviation score (BMI SD score) in patients younger than 18 years of age and classified them as obese when the BMI SD score was $\geq+2$ SD. The normal range was between $-2 \mathrm{SD}$ and $+2 \mathrm{SD}$ in children. In patients older than 18 years at the time of follow-up, BMI was used for determining obesity.

\section{Statistical Analysis}

The data are expressed as the mean \pm SD in normally distributed samples and as the median and interquartile range (IQR) in nonnormally distributed samples. Statistical analyses were performed with JMP software (version 9.0.2, SAS Institute Inc.) using the Fisher exact test, MannWhitney U-test, Student t-test, or Welch t-test. Multivariate stepwise logistic regression analyses were performed to detect significant independent factors using factors that had significant associations in univariate analyses. A p value $<0.05$ was considered statistically significant.

\section{Results \\ Patient Characteristics}

The 65 pediatric craniopharyngioma patients consisted of 28 girls and 37 boys who had a mean age of 9.6 years (range 0.8-17.9 years) at the time of surgery (Table 1). Forty-five patients $(69.2 \%)$ had no previous surgeries, although prior external ventricle drainage had been performed in 2 patients, followed by ventriculoperitoneal (VP) shunt placement in 1 patient for the treatment of complicated hydrocephalus. The remaining 20 patients had undergone prior surgeries. Seventeen patients had undergone a total of 26 craniotomies; 9 of these patients had each undergone 1 craniotomy (before the craniotomy, 2 patients had VP shunt placement and 1 patient had external ventricle drainage), 7 patients had undergone 2 craniotomies (1 patient had preoperative external ventricle drainage and 2 patients had Gamma Knife and CyberKnife treatment after surgery for each intervention), and 1 patient had undergone 3 craniotomies and CyberKnife treatment. Of the remaining 3 patients, 2 had conventional TSS and 1 had VP shunt placement followed by Ommaya reservoir placement with nimustine hydrochloride administration and 3 Gamma Knife treatments. These prior treatments were performed at outside institutions in all but 1 patient, who had undergone a prior craniotomy at our own institution performed by another surgeon 1 year before the TSS described herein.

\section{Clinical Presentation}

The initial symptoms that led to the detection of craniopharyngioma are summarized in Table 1 . Of the 45 patients without prior surgical intervention, the most prevalent initial symptom was visual disturbance (27\%), followed by short stature (22\%), the combination of headache and vomiting (13\%), and headache without vomiting (9\%). Interestingly, in 2 patients, craniopharyngioma was serendipitously found during an MRI evaluation for head trauma. Of the 20 patients who had undergone prior surgery, the most common initial symptom was headache and vomiting due to increased intracranial pressure (50\%). In these 20 patients, the reasons for repeat surgery performed at our institution included tumor recurrence or regrowth 
TABLE 1. Characteristics of our 65 pediatric patients with craniopharyngioma

\begin{tabular}{lc}
\hline \multicolumn{1}{c}{ Characteristic } & Value \\
\hline Total no. of pts & 65 \\
\hline No. of pts alive at last follow-up & 65 \\
\hline No. of pts followed for $>5$ yrs & 40 \\
\hline Age (yrs) & \\
\hline$\quad$ Mean \pm SD & $9.6 \pm 4.4$ \\
\hline Range & $0.8-17.9$ \\
\hline Sex & \\
\hline Female & 28 \\
\hline Male & 37 \\
\hline
\end{tabular}

First symptom

Visual disturbance

Pts who underwent primary surgery $\quad 12 / 45$

Pts who underwent repeat surgery $\quad 3 / 20$

Short stature

Pts who underwent primary surgery $\quad$ 10/45

Pts who underwent repeat surgery $\quad$ 0/20

Headache \& vomiting (increased intracranial pressure)

Pts who underwent primary surgery 6/45

Pts who underwent repeat surgery $\quad 10 / 20$

Headache

Pts who underwent primary surgery $\quad$ 4/45

Pts who underwent repeat surgery $\quad 3 / 20$

Short stature \& secondary sexual feature disturbance

Pts who underwent primary surgery $\quad$ 4/45

Pts who underwent repeat surgery $\quad 0 / 20$

Visual disturbance \& headache

Pts who underwent primary surgery $\quad 2 / 45$

Pts who underwent repeat surgery $\quad 1 / 20$

Short stature \& headache

Pts who underwent primary surgery 2/45

Pts who underwent repeat surgery $\quad 0 / 20$

Incidental finding in MRI for head trauma

Pts who underwent primary surgery 2/45

Pts who underwent repeat surgery $\quad 0 / 20$

Visual disturbance \& short stature

Pts who underwent primary surgery $\quad 1 / 45$

Pts who underwent repeat surgery $\quad 0 / 20$

Polyuria

Pts who underwent primary surgery $\quad 1 / 45$

Pts who underwent repeat surgery $\quad 2 / 20$

Consciousness disturbance \& convulsion (adrenal crisis)

Pts who underwent primary surgery $\quad 1 / 45$

Pts who underwent repeat surgery $\quad 0 / 20$

Convulsion

Pts who underwent primary surgery $\quad 0 / 45$

Pts who underwent repeat surgery $\quad 1 / 20$

Cause for repeat TSS in 20 patients

Tumor recurrence or regrowth 9

Visual disturbance \& tumor recurrence or regrowth 6

CONTINUED IN NEXT COLUMN »

J Neurosurg Pediatr Volume 21 • June 2018
» CONTINUED FROM PREVIOUS COLUMN

TABLE 1. Characteristics of our 65 pediatric patients with craniopharyngioma

\begin{tabular}{|c|c|}
\hline Characteristic & Value \\
\hline \multicolumn{2}{|l|}{ Cause for repeat TSS in 20 patients (continued) } \\
\hline Large residual tumor & 4 \\
\hline Headache \& tumor recurrence or regrowth & 1 \\
\hline
\end{tabular}

alone (45\%), exacerbation of visual function and tumor recurrence or regrowth (30\%), and the presence of a large residual tumor $(20 \%)$ (Table 1).

\section{Preoperative Neuroimaging Findings}

Tumor characteristics were assessed based on neuroimaging findings (CT and MRI) and histological analysis (Table 2). In the 20 patients with repeat surgery, imaging assessments were based on images obtained just prior to the repeat surgery performed at our hospital. Of the 45 primary surgery patients, 26 had subdiaphragmatic tumors, of which 3 were of the sellar subtype (7\%) and 23 of the suprasellar subtype (51\%), and 19 had supradiaphragmatic tumors (42\%), of which 1 was purely intraventricular (Fig. 1) ${ }^{47}$ Of the 20 repeat surgery patients, 2 had sellar tumors, 7 had suprasellar tumors, and 11 had supradiaphragmatic tumors. All tumors from both groups were mixed cystic and solid (54\%) or purely cystic (46\%), and there were no

TABLE 2. Tumor characteristics in 65 pediatric patients who underwent transsphenoidal surgery

\begin{tabular}{lccc}
\hline Tumor Characteristic & $\begin{array}{c}\text { Primary } \\
\text { Surgery }\end{array}$ & $\begin{array}{l}\text { Repeat } \\
\text { Surgery }\end{array}$ & Total \\
\hline Tumor type & & & \\
\hline Subdiaphragmatic & & & \\
\hline Sellar type & $3(7)$ & $2(10)$ & $5(8)$ \\
\hline Suprasellar type & $23(51)$ & $7(35)$ & $30(46)$ \\
\hline Supradiaphragmatic & $19(42)^{*}$ & $11(55)$ & $30(46)$ \\
\hline Tumor size & & & \\
\hline Small $(<2$ cm) & $2(4)$ & $3(15)$ & $5(8)$ \\
\hline Moderate $(2-4$ cm) & $32(71)$ & $16(80)$ & $48(74)$ \\
\hline Large $(>4$ cm) & $11(24)$ & $1(5)$ & $12(19)$ \\
\hline Tumor content & & & \\
\hline Cystic & $23(51)$ & $7(35)$ & $30(46)$ \\
\hline Mixed & $22(49)$ & $13(65)$ & $35(54)$ \\
\hline Solid & $0(0)$ & $0(0)$ & $0(0)$ \\
\hline Hypothalamic involvement & & & \\
\hline Grade 0 & $19(42)$ & $10(50)$ & $29(45)$ \\
\hline Grade 1 & $8(18)$ & $3(15)$ & $11(17)$ \\
\hline Grade 2 & $18(40)$ & $7(35)$ & $25(38)$ \\
\hline
\end{tabular}

Data are numbers of cases $(\%)$.

* Of these 19 supradiaphragmatic tumors, one was a purely intraventricular craniopharyngioma. 

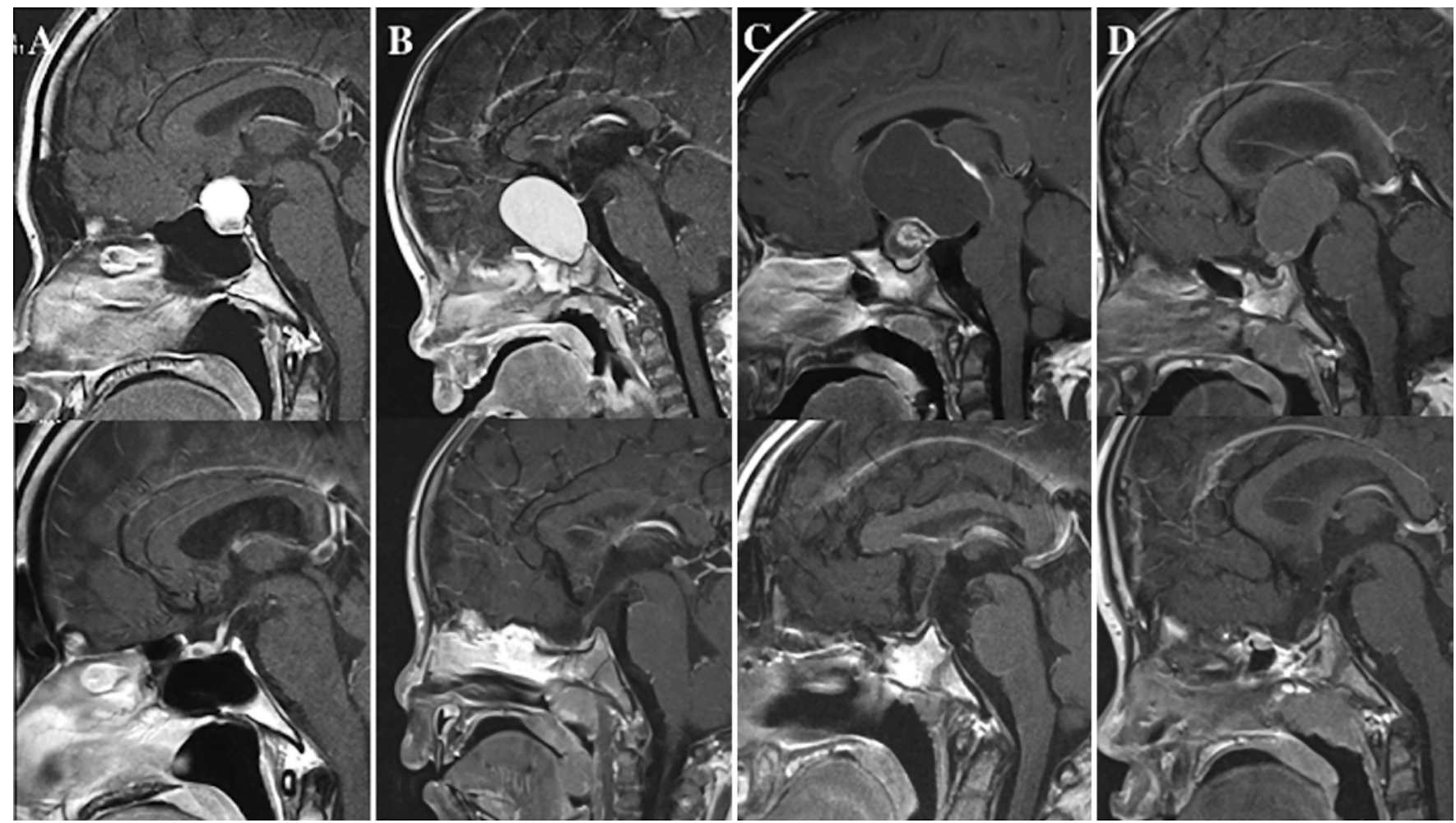

FIG. 1. Preoperative (upper) and postoperative (lower) T1-weighted, enhanced sagittal MR images from representative cases for each type of craniopharyngioma. A: Sellar type. The tumor was completely removed with pituitary stalk (PS) preservation. The patient was female and was 15 years old at the time of surgery. As of 15 years after surgery, the tumor had not recurred and the patient had normal pituitary function. B: Suprasellar type. The tumor was completely removed with PS preservation. The patient was male and was 8 months old at the time of surgery. There was no tumor recurrence and the patient's preoperative visual disturbance improved, but he had panhypopituitarism plus DI after surgery (still present at 2.5 years' follow-up). C: Supradiaphragmatic type. The tumor was completely removed without PS preservation. The patient was male and was 3 years old at the time of surgery. As of 10 years after surgery, the tumor had not recurred and the patient had no distinct hypothalamic disturbance. D: Purely intraventricular type. The tumor was completely removed without PS preservation. The patient was male and was 5 years old at the time of surgery. As of 3 years after surgery, the tumor had not recurred and there was no distinct hypothalamic disturbance.

cases of purely solid tumors. Moreover, calcification was observed in 54 cases (83\%). Regarding hypothalamic involvement, which was graded based on preoperative MRI, 29 cases were grade 0,11 were grade 1 , and 25 were grade 2. Statistical analyses of these data showed that there were no differences between the 2 surgical groups with respect to tumor type $(p=0.2)$, presence of calcification $(p=0.7)$, degree of hypothalamic involvement $(p=0.7)$, or histological category (cystic, solid, or mixed) $(p=0.4)$. However, in terms of tumor size, the median maximum tumor diameter was $30 \mathrm{~mm}$ (range $14-60 \mathrm{~mm}$ ) in the primary surgery group and $25 \mathrm{~mm}$ (range 10-42 $\mathrm{mm}$ ) in the repeat surgery group, and large tumors $(>4 \mathrm{~cm})$ were more common in the primary surgery patients than in the repeat surgery patients $(\mathrm{p}=0.008)$.

\section{Tumor Removal Outcomes}

The surgical outcomes are summarized in Fig. 2. None of the patients died perioperatively. The desired surgical outcome was GTR, except when GTR was contraindicated. GTR was considered to have been achieved (based on intraoperative assessment and confirmed by postoperative MRI) in 59 (91\%) of the 65 cases (Fig. 1). In the primary surgery group, GTR was achieved in 44 (98\%) of the 45 cases, whereas it was achieved in only $15(75 \%)$ of the 20 repeat surgeries, demonstrating a reduction in the desired outcome in repeat surgery patients $(\mathrm{p}=0.009$; Table 3$)$. One of the primary surgery patients was operated on via a simultaneous combined supra- and infrasellar approach for a giant cystic tumor, ${ }^{48}$ which resulted in an STR due to adherence of the tumor to the anterior communicating artery (Fig. 3). In terms of surgical methods, a pure endoscopic TSS was performed in the most recent 19 cases, and there were no significant differences between the percentages of primary and repeat surgeries performed using microscopic compared with endoscopic TSS. GTR was achieved in 42 (91.3\%) of 46 patients operated on with microscopic TSS and 17 (89.5\%) of the 19 patients operated on with endoscopic TSS, indicating that there is no significant difference between these methods in terms of tumor removal outcome $(\mathrm{p}>0.99)$. The reasons for incomplete tumor excision were firm attachment to, fibrous adhesion to, or invasion of the surrounding structures, including the optic chiasm and hypothalamus.

We also analyzed additional factors, such as age, sex, tumor size, tumor component, and tumor calcification, for 


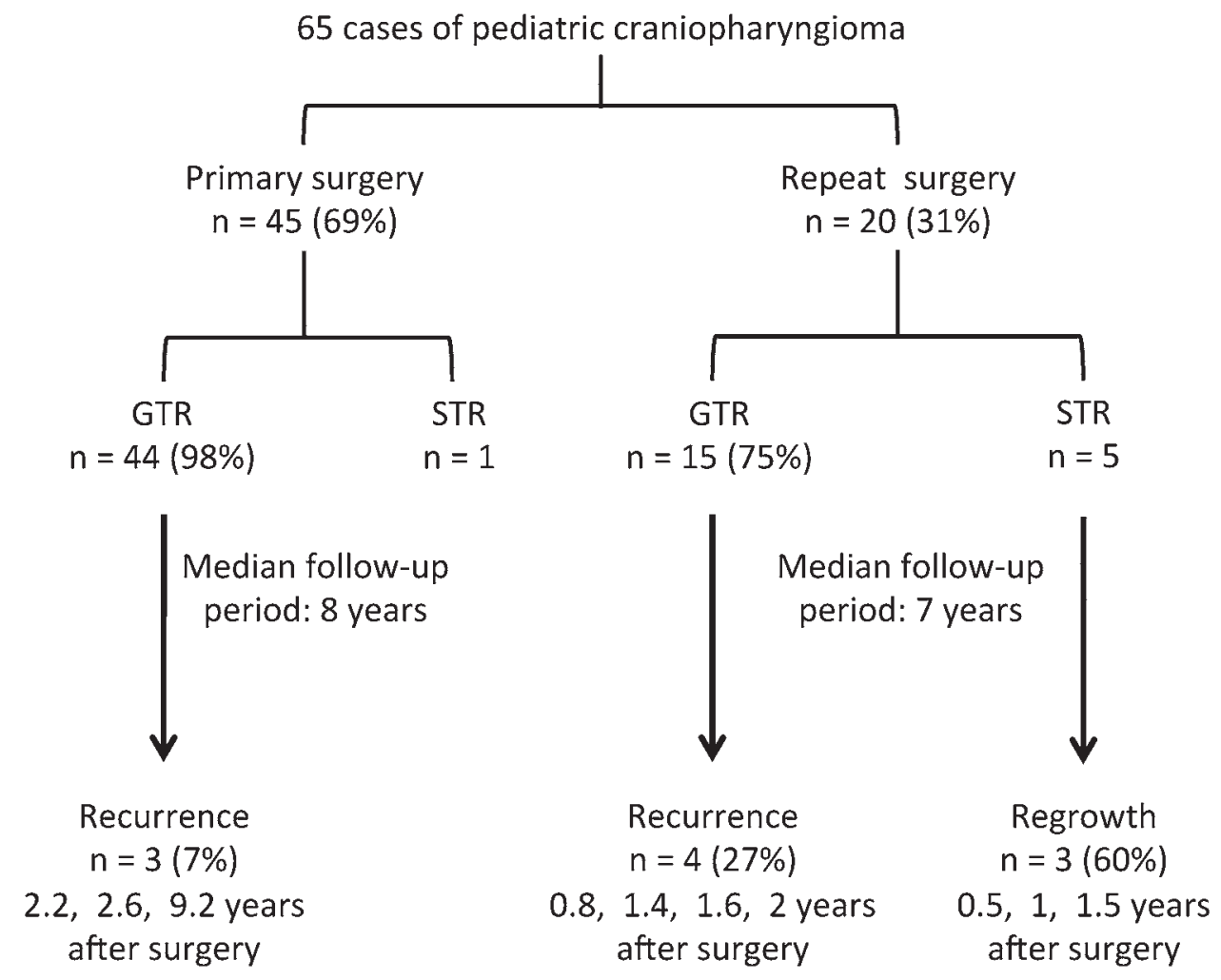

FIG. 2. Flowchart illustrating the outcomes of surgery in our 65 pediatric patients with craniopharyngioma. Two of 5 patients underwent radiotherapy after surgery.

any statistical relationship with tumor removal outcome (Table 3). The rate of total tumor removal was higher for the smaller tumors $(p=0.008)$ and for the mainly cystic tumors $(\mathrm{p}=0.03)$; however, the other factors showed no significant differences in tumor removal outcome. Moreover, multivariate stepwise logistic regression analyses showed that there were no statistically significant, independent factors influencing total tumor removal (Table 3).

\section{Follow-Up Results}

Follow-up data were available for all 65 patients. The median duration of follow-up for the entire cohort was 93 months (7.8 years; range $15-307$ months). Of the 44 primary surgery patients with GTR, only 3 (7\%) experienced tumor recurrence (at 2.2, 2.6, and 9.2 years after surgery). These 3 patients underwent CyberKnife treatment, and the recurrent tumors were almost undetectable on the followup MRI. The primary surgery patient with STR has been followed up for 3.5 years since surgery without regrowth of the residual tumor (Fig. 2). This patient continues to be monitored, and if tumor regrowth is identified in follow-up MRI, we plan to treat the patient with radiosurgery because of the small residual tumor. In contrast, of the 15 repeat surgery patients with GTR, $4(27 \%)$ had tumor recurrence (at 0.8, 1.4 1.6, and 2 years after surgery) (Fig. 2 ), suggesting that tumor recurrence is more common in the repeat surgery patients than in the primary surgery patients; however, the difference was not statistically significant $(\mathrm{p}=0.06)$. Of the 5 repeat surgery patients with STR, $3(60 \%)$ showed tumor regrowth (at $0.3,1$, and 1.5 years after surgery), and the remaining 2 patients received CyberKnife treatment 2-3 months after surgery. The 7 repeat surgery patients receiving radiosurgery after tumor recurrence or regrowth are continuing to be followed up, and to date, they have shown no further progression of these residual tumors.

\section{Visual Outcomes}

We assessed patients' preoperative and postoperative vision according to their surgery type (Table 4). Preoperatively, visual disturbance was found subjectively or objectively in 45 (73\%) of 62 patients. Three patients could not be assessed due to their young age. One of the 17 patients with normal preoperative vision experienced postoperative visual deterioration. Of the 45 patients with preoperative visual impairment, 28 (62\%) showed improved or normalized vision, 12 (27\%) had no change, and 5 (11\%) experienced worsening of their impairment after surgery. Analysis by surgery group showed that postoperative visual improvement occurred in $20(71 \%)$ of 28 primary surgery patients compared with $8(47 \%)$ of 17 repeat surgery patients, demonstrating that visual improvement was more likely to occur following primary surgery than repeat surgery $(\mathrm{p}<0.001)$. Moreover, visual deterioration was also less frequent following primary surgery $(4 \%)$ than following repeat surgery $(24 \%)(p=0.04)$.

\section{Endocrine Outcomes}

Among the 65 patients, normal pituitary function, partial hypopituitarism, and panhypopituitarism with or with- 
TABLE 3. Factors influencing extent of tumor resection

\begin{tabular}{|c|c|c|c|}
\hline Factor & GTR & STR & $p$ Value \\
\hline \multicolumn{4}{|l|}{ Univariate analyses } \\
\hline Mean age (yrs) & $9.5 \pm 4.3$ & $9.8 \pm 6.1$ & 0.88 \\
\hline Sex & & & 0.22 \\
\hline Female & 27 & 1 & \\
\hline Male & 32 & 5 & \\
\hline Type of surgery & & & 0.009 \\
\hline Primary & 44 & 1 & \\
\hline Repeat & 15 & 5 & \\
\hline Tumor size (mm) & & & 0.008 \\
\hline Median & 27 & 32 & \\
\hline IQR & $23-35$ & $28-42$ & \\
\hline Tumor component & & & 0.027 \\
\hline Cystic & 30 & 0 & \\
\hline Mixed & 29 & 6 & \\
\hline Tumor calcification & & & 0.58 \\
\hline Present & 48 & 6 & \\
\hline Absent & 11 & 0 & \\
\hline \multicolumn{4}{|c|}{ Multivariate analyses } \\
\hline Type of surgery & & & 0.072 \\
\hline Primary & 44 & 1 & \\
\hline Repeat & 15 & 5 & \\
\hline Tumor size (mm) & & & 0.075 \\
\hline Median & 27 & 32 & \\
\hline IQR & $23-35$ & $28-42$ & \\
\hline Tumor component & & & 0.997 \\
\hline Cystic & 30 & 0 & \\
\hline Mixed & 29 & 6 & \\
\hline
\end{tabular}

Data are numbers of cases unless otherwise indicated. Mean values are presented with SDs.

out diabetes insipidus (DI) were found in $6(9 \%), 28(43 \%)$, and $31(48 \%)$, respectively. In the primary surgery group, DI was found in 4 of 15 patients with panhypopituitarism and 1 of 24 with partial hypopituitarism, accounting for a
TABLE 4. Preoperative and postoperative visual status in 62 pediatric patients with craniopharyngioma

\begin{tabular}{cccc}
\hline Vision Status & Primary Surgery & Repeat Surgery & Total \\
\hline Preop & & & \\
\hline Normal & $14^{*}$ & 3 & 17 \\
\hline Impaired & 28 & 17 & 45 \\
\hline Postop & & & \\
\hline Improved & $20 / 28(71 \%)$ & $8 / 17(47 \%)$ & $28 / 45(62 \%)$ \\
\hline Unchanged & $7 / 28(25 \%)$ & $5 / 17(29 \%)$ & $12 / 45(27 \%)$ \\
\hline Worsened & $1 / 28(4 \%)$ & $4 / 17(24 \%)$ & $5 / 45(11 \%)$ \\
\hline
\end{tabular}

Data are numbers of patients. A detailed assessment of vision was impossible in 3 patients and they were excluded from this analysis.

* One of the 14 patients with normal vision showed postoperative visual deterioration.

total of $5(11 \%)$ of 45 cases (Table 5). In the repeat surgery group, DI was found in 15 of 16 patients with panhypopituitarism and 1 of 4 with partial hypopituitarism, accounting for a total of $16(80 \%)$ of 20 cases (Table 5); thus, DI was more frequent in repeat surgery patients than in primary surgery patients $(\mathrm{p}<0.001)$. Postoperative improvement of anterior pituitary hormone levels was not found in any patients with preoperative partial hypopituitarism or panhypopituitarism. In contrast, deterioration of pituitary function occurred in $24(80 \%)$ of 30 primary surgery patients and $4(100 \%)$ of 4 repeat surgery patients with preoperative normal pituitary function or partial hypopituitarism (Table 5). Postoperative DI developed in 33 (83\%) of 40 primary surgery patients and in $4(100 \%)$ of 4 repeat surgery patients without preoperative DI, and none of the patients with preoperative DI showed improvement after surgery. In the primary surgery group, deteriorated pituitary function tended to be more common in patients with preoperative partial hypopituitarism (21 [88\%] of 24) than in patients with preoperative normal pituitary function (3 [50\%] of 6), although this difference was not statistically significant $(\mathrm{p}=0.27)$.

Preservation of the pituitary stalk was attempted during surgery in the 50 patients without preoperative panhypo-
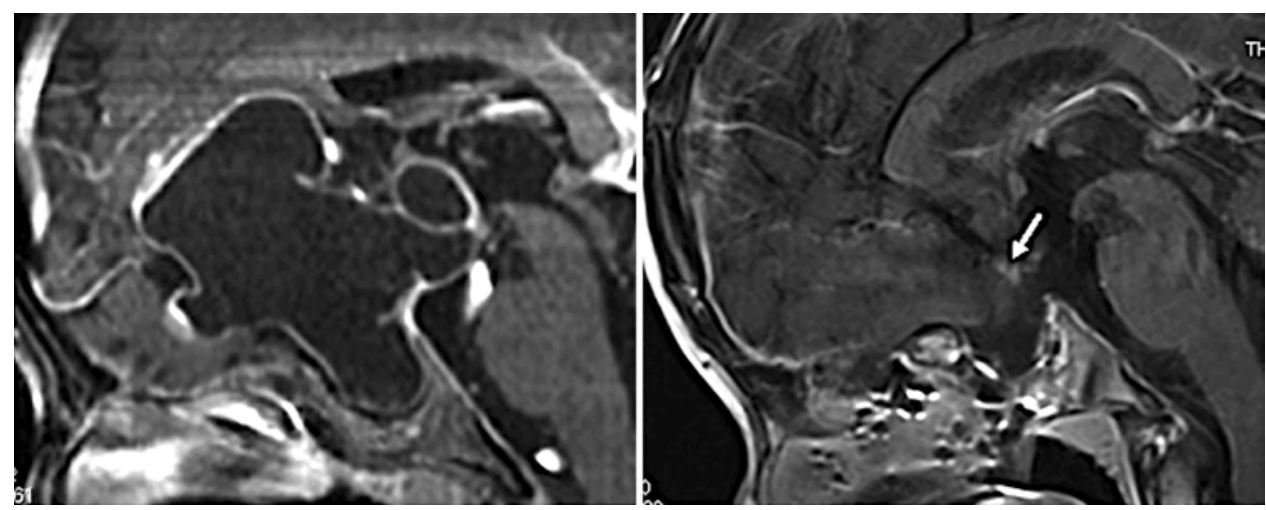

FIG. 3. Preoperative (left) and postoperative (right) sagittal, T1-weighted, enhanced MR images obtained in a 5-year-old boy who suffered from a visual disturbance, especially on the left side, and panhypopituitarism with partial DI. The preoperative MR image shows a large, mainly cystic lesion with an anterior suprasellar extension. STR was performed using a simultaneous combined supra- and infrasellar approach, leaving a small remnant adhering to the anterior communicating artery (arrow). 
TABLE 5. Preoperative and postoperative endocrine function in 45 patients who underwent primary surgery and 20 patients who underwent repeat surgery

\begin{tabular}{|c|c|c|c|c|c|c|}
\hline \multirow[b]{2}{*}{ Variable \& Group } & \multirow[b]{2}{*}{ Preop } & \multicolumn{5}{|c|}{ Postop } \\
\hline & & Improved & Unchanged & Worse & New Deficit* & Deterioration $†$ \\
\hline \multicolumn{7}{|l|}{ Pituitary dysfunction } \\
\hline Primary surgery pts & & 0 & $18(46 \%)$ & $21(54 \%)$ & $3 / 6(50 \%)$ & $24 / 30(80 \%) \ddagger$ \\
\hline Partial & $24(53 \%)$ & & & & & \\
\hline Panhypopit & $15(33 \%)$ & & & & & \\
\hline Repeat surgery & & 0 & $16(80 \%)$ & $4(20 \%)$ & $0 / 0(0 \%)$ & $4 / 4(100 \%)$ \\
\hline Partial & $4(20 \%)$ & & & & & \\
\hline Panhypopit & $16(80 \%)$ & & & & & \\
\hline \multicolumn{7}{|l|}{$\mathrm{DI}$} \\
\hline Primary surgery & $5(11 \%)$ & 0 & $5(100 \%)$ & 0 & $33 / 40(83 \%)$ & $33 / 40(83 \%)$ \\
\hline Repeat surgery & $16(80 \%)$ & 0 & $16(100 \%)$ & 0 & $4 / 4(100 \%)$ & $4 / 4(100 \%)$ \\
\hline
\end{tabular}

Panhypopit = panhypopituitarism.

Values are numbers of patients.

* New deficit in patients who did not have that particular deficit preoperatively.

$\dagger$ Patients with new deficit plus patients with worsening of endocrine function.

$\ddagger$ This group of 30 patients includes 24 who had partial pituitary dysfunction preoperatively and 6 who had normal pituitary function preoperatively.

pituitarism and DI, and as a result, it was morphologically preserved in $23(46 \%)$ of 50 patients. Postoperatively, 3 of these 23 patients had normal pituitary function, 1 had partial hypopituitarism, 2 had partial hypopituitarism plus DI, 1 had panhypopituitarism, and 16 had panhypopituitarism plus DI, indicating that, despite the morphological preservation of the pituitary stalk during surgery, the majority of patients still develop panhypopituitarism with DI.

\section{Postoperative Complications}

Postoperative complications, other than endocrine or

TABLE 6. Complications other than endocrine and visual impairment in 65 patients with pediatric craniopharyngioma

\begin{tabular}{cccc}
\hline \multicolumn{1}{c}{ Complication } & $\begin{array}{c}\text { Primary } \\
\text { Surgery (\%) }\end{array}$ & $\begin{array}{c}\text { Repeat } \\
\text { Surgery (\%) }\end{array}$ & Total (\%) \\
\hline CSF leak & $2 / 45(4.4)$ & $4 / 20(20)$ & $6 / 65(9.2)$ \\
\hline w/ meningitis & 2 & 2 & $4 / 65(6.2)$ \\
\hline w/ hydrocephalus & 0 & 2 & $2 / 65(3.1)$ \\
\hline Transient & 0 & 0 & 0 \\
\hline Requiring add'l surgery & 2 & $4^{*}$ & $6 / 65(9.2)$ \\
\hline Meningitis & $1 / 45(2.2)$ & $2 / 20(10)$ & $3 / 65(4.6)$ \\
\hline Hydrocephalus & 0 & 1 & $1 / 65(1.5)$ \\
\hline Vascular injury & 0 & 0 & 0 \\
\hline Cranial nerve palsy & 0 & 0 & 0 \\
\hline Hypothalamic dysfunction & $2 / 45(4.4)$ & $0 \dagger$ & $2 / 65(3.1)$ \\
\hline Transient & 2 & 0 & $2 / 65(3.1)$ \\
\hline Add' & & &
\end{tabular}

Add'l = additional.

* Including 2 VP shunt placement procedures.

$\dagger$ Various hypothalamic dysfunctions (memory disturbance, impaired thirst, temperature instability) were already found in 5 patients before repeat surgery, and 4 patients had to attend a school for disabled children at the time of final follow-up. visual impairment, occurred in $12(18 \%)$ of 65 patients, including 6 with CSF leaks, 3 with meningitis, 2 with recent memory disturbances, and 1 with postoperative hydrocephalus (Table 6). Of the 6 cases of CSF leakage, 4 were associated with meningitis and all 6 required surgery (including VP shunt placement in 2 cases) to repair or control CSF leakage. Postoperative CSF leakage appeared to be more common in repeat surgery patients (4 [20\%] of 20) than in primary surgery patients (2 [4.4\%] of 45); however, this apparent difference was not statistically significant $(p=0.2)$. In contrast, the frequency of postoperative CSF leakage was significantly lower after the introduction of a septal flap (with CSF leakage occurring in 1 [5.9\%] of 17 cases) compared with the use of a fascia dural flap alone (4 [12\%] of 34 cases) $(p=0.02)$. Moreover, no primary surgery patient required postoperative VP shunt placement to control CSF leakage. Analysis by surgical method showed that $10(21.7 \%)$ of the 46 patients who underwent microscopic TSS showed these complications, whereas $2(10.5 \%)$ of the 19 patients who underwent endoscopic TSS showed these complications, demonstrating that there was no significant difference between the methods with respect to postoperative complications $(\mathrm{p}=0.5)$.

\section{Obesity}

Obesity was identified preoperatively in 2 of 45 primary surgery patients and in 6 of 20 repeat surgery patients; thus, preoperative obesity was higher in the repeat surgery group ( $\mathrm{p}<0.01$ ) (Fig. 4). At the time of final follow-up, new-onset postoperative obesity had been diagnosed in 4 (9\%) of the remaining 43 primary surgery patients and in $3(21 \%)$ of the remaining 14 repeat surgery patients; this difference was not statistically significant $(\mathrm{p}=0.33)$.

\section{Histological Findings}

We confirmed the presence of craniopharyngioma in all patients by histological analysis of their tumor speci- 
BMI SDS

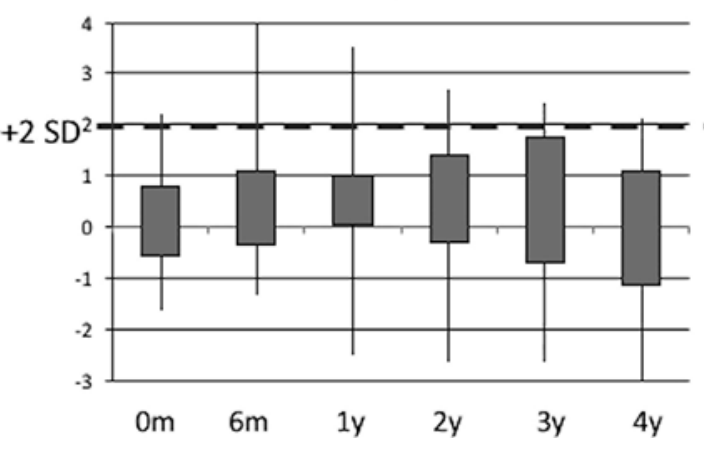

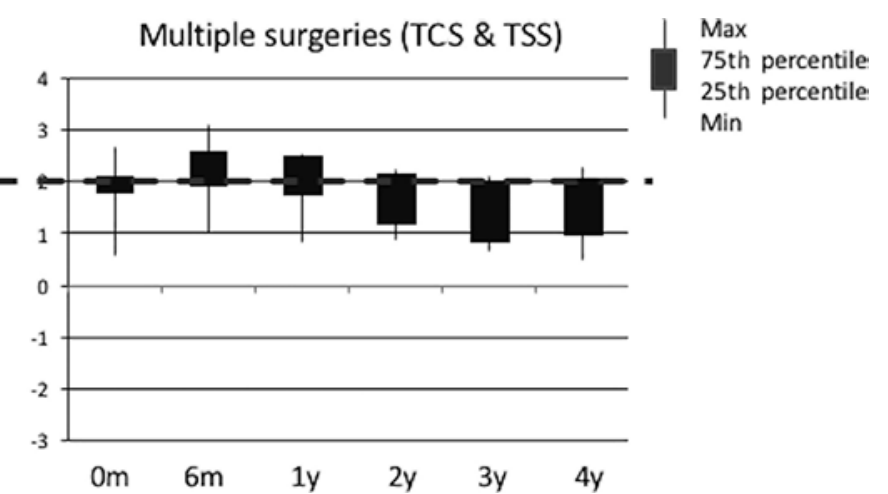

FIG. 4. Change in BMI SD scores (SDS) in 20 pediatric craniopharyngioma patients (9 boys and 11 girls, age range 3.2-15.8 years) who underwent GTR between 1991 and 2009. Thirteen had TSS as their primary surgery, whereas 7 had TCS followed by TSS at repeat surgery. The mean values of the BMI SD scores were higher in repeat surgery patients than in primary TSS surgery patients. There was a transient postoperative increase in BMI SD scores in both groups. $m=$ months; $y=$ year(s).

mens. Based on their morphological appearance, 53 tumors $(82 \%)$ were classified as the adamantinomatous subtype and 12 tumors (18\%) as the squamous papillary subtype. Comparison of the frequency of the adamantinomatous subtype in the subdiaphragmatic and supradiaphragmatic tumor groups showed no significant difference (26 [74\%] of 35 subdiaphragmatic tumors vs 27 [90\%] of 30 supradiaphragmatic tumors, $\mathrm{p}=0.94$ ).

\section{Discussion}

\section{ExTSS for Craniopharyngioma}

The surgical management of craniopharyngiomas is challenging because of their close proximity to crucial structures of the parasellar region. TSS has been traditionally used for the treatment of subdiaphragmatic craniopharyngiomas, which are located either totally or mainly within an enlarged sella. ${ }^{1}$ Previously, TSS had been considered a contraindication for lesions originating in, or extending into, the extrasellar space with a normal-size sella $;{ }^{8}$ however, the transsphenoidal removal of supradiaphragmatic craniopharyngiomas became possible through adoption of exTSS, which was originally described by Weiss in $1987 .{ }^{60}$ This approach, which involves removal of the tuberculum sellae and planum sphenoidale, has several advantages. 1) It offers excellent midline access and visibility to the suprasellar region without brain retraction. 2) It permits early exposure of the suprasellar lesion. 3) It provides good visualization of the pituitary gland and stalk and the main vascular structures. 4) It minimizes manipulation of the optic apparatus. Thus, in the 1990s, neurosurgeons began using exTSS with a surgical microscope to remove supradiaphragmatic craniopharyngiomas, ${ }^{14,32,33,36,42,61}$ and more recently, the use of TSS with an endoscope has become more common in craniopharyngioma treatment. ${ }^{5,6,10,21,30,38,41}$ At Toranomon Hospital, in 1998, we also began using exTSS with an endoscope-assisted microscope for the treatment of supradiaphragmatic craniopharyngiomas, and in 2012, we switched to purely endoscopic TSS. Consequently, in the past 10 years, we treated 93\% of the pediatric craniopharyngioma patients at Toranomon Hospital with TSS.

\section{Indication for TSS in Craniopharyngioma}

There is still considerable debate about the indication for TSS, and exTSS is contraindicated in certain types of craniopharyngiomas, including tumors with far-lateral extension beyond the internal carotid arteries or far-anterior extension, purely intraventricular tumors, and tumors with major suprasellar calcifications, because this approach is not likely to allow safe and complete removal of these tumor types, even with endoscopy. These tumors should be removed by TCS; ;,10,21,30,38,41 4 craniopharyngioma patients who underwent TCS during the past 10 years at our institute had such contraindications for TSS (3 had lesions with far-lateral extension beyond the internal carotid arteries and 1 had a purely intraventricular tumor). However, 1 patient who had a craniopharyngioma with far-anterior extension underwent successful resection with a simultaneous combined approach (Fig. 4). ${ }^{48}$ Therefore, we believe that craniopharyngiomas with far-anterior or far-lateral extension should be removed by TCS or a simultaneous combined approach if the intrasellar and/or suprasellar tumor portion is determined to be amenable to resection by exTSS. Similarly, major suprasellar calcifications are contraindicated for TSS. Dissection of a severely calcified tumor or tumor capsule from the surrounding brain tissue through a narrow operative corridor may result in injury to surrounding brain tissue or blood vessels. ${ }^{7,23}$ In contrast, it is still controversial whether purely third ventricular craniopharyngioma is a contraindication for TSS. Although some authors insist that this type of tumor should be removed via TCS, ${ }^{30,35}$ others argue that it can be removed via exTSS by removing tumor below and above the optic chiasm. ${ }^{10,34}$ Previously, we recommended that a purely intraventricular craniopharyngioma should be removed via TCS because excising the tumor from below and above the optic chiasm could disrupt optic function ${ }^{61}$ However, we have recently used endoscopic exTSS to effectively and safely remove 3 purely intraventricular craniopharyngiomas, one of which we reported in this study. Thus, a purely intraventricular craniopharyngioma with inferior extension into the interpeduncular fossa with anterior displacement of the chiasm may be a suitable candidate for exTSS. ${ }^{47}$ 
TABLE 7. Summary of outcomes in studies on extended endonasal approach for the treatment of pediatric craniopharyngiomas

\begin{tabular}{|c|c|c|c|c|c|c|c|c|c|c|c|c|}
\hline \multirow[b]{2}{*}{ Authors \& Year } & \multirow{2}{*}{$\begin{array}{c}\text { Mean } \\
\text { Age in Yrs } \\
\text { (range) }\end{array}$} & \multirow{2}{*}{$\begin{array}{l}\mathrm{M} / \mathrm{F} \\
\text { Ratio }\end{array}$} & \multicolumn{2}{|c|}{ No. of Pts } & \multicolumn{3}{|c|}{ GTR, STR, PR } & \multirow{2}{*}{$\begin{array}{c}\text { Vision } \\
\text { Impr (\%) }\end{array}$} & \multirow{2}{*}{$\begin{array}{c}\text { New } \\
\text { Hypopit } \\
(\%)\end{array}$} & \multirow{2}{*}{$\begin{array}{c}\text { New } \\
\text { Perm DI } \\
(\%)\end{array}$} & \multirow{2}{*}{$\begin{array}{c}\text { CSF } \\
\text { Leak } \\
(\%)\end{array}$} & \multirow{2}{*}{$\begin{array}{c}\text { Recur Rate } \\
(\%)\end{array}$} \\
\hline & & & Total & $\mathrm{RS}^{*}$ & All Ops (\%) & PS & RS & & & & & \\
\hline Jane et al., 2010 & $12(3-17)$ & 1 & 22 & 11 & 15 (68), 5 (18), 2 (9) & $11,0,0$ & $4,5,2$ & $9 / 14(64)$ & $6 / 9(67)$ & $5 / 9(56)$ & $2(9)$ & 4/22 (18)† \\
\hline Leng et al., 2012 & $10(5-15)$ & 2 & 3 & 0 & $2(67), 1(33), 0(0)$ & & & NA & $1 / 3(33)$ & $1 / 3(33)$ & 0 & $0 / 3$ \\
\hline $\begin{array}{l}\text { Koutourousiou et } \\
\text { al., } 2013\end{array}$ & $9(4-18)$ & 1.8 & 17 & 4 & $9(53), 8(47), 0(0)$ & & & $6 / 6(100)$ & $13 / 15(87)$ & $11 / 14(79)$ & $2(12)$ & $7 / 17(41)$ \\
\hline Cavallo et al., 2014 & $10(3-16)$ & 1 & 20 & 8 & $14(70), 5(25), 1(5)$ & $11,1,0$ & $3,4,1$ & $12 / 13(92)$ & $9 / 17(53)$ & $8 / 14(57)$ & $1(5)$ & NA \\
\hline $\begin{array}{l}\text { Sankhla et al., } \\
2015\end{array}$ & $12(8-15)$ & 0.7 & 15 & 9 & $10(67), 4(27), 1(7)$ & $6,0,0$ & $4,4,1$ & $11 / 15(73)$ & $5 / 15(33)$ & $3 / 15(20)$ & $3(20)$ & NA \\
\hline Current series & $10(1-18)$ & 1.3 & 65 & 20 & $59(91), 6(9), 0(0)$ & $44,1,0$ & $15,5,0$ & $28 / 45(62)$ & $24 / 30(80)$ & $37 / 44$ (84) & $6(9)$ & $10 / 65(15) \ddagger$ \\
\hline
\end{tabular}

Hypopit = hypopituitarism; impr = improvement; NA = not available; perm = permanent; PR = partial resection; $P S=$ primary surgery; recur = recurrence; $R S=$ repeat surgery.

Values are numbers of patients (\%) unless otherwise indicated.

* Number of patients who underwent repeat surgery.

† The recurrence rate was $13 \%$ in patients who underwent GTR and $29 \%$ in those who underwent STR or partial resection.

$\ddagger$ The recurrence rate was $12 \%$ in patients who underwent GTR and $50 \%$ in those who underwent STR or partial resection.

Some investigators have reported that the nonpneumatized sphenoid sinuses of young children make the endonasal approach more difficult, requiring a greater degree of bone removal and drilling. ${ }^{35,55,63}$ However, the bony structure filling in the sphenoidal sinuses of young children is not hard bone but a marrow substance that is easily resected, leaving the cortical bone of the skull base safely intact, including the bony sellar floor. Indeed, there was no patient in this series in whom a nonpneumatized sphenoid sinus was an obstacle to performing TSS. Moreover, our current series included 5 patients younger than 3 years of age, with the youngest patient being 11 months old, and we successfully removed their tumors via exTSS without any complications. Therefore, we strongly disagree with the opinion that TSS is not possible in children younger than 3 years of age, the age when pneumatization of the sphenoid sinuses begins. ${ }^{20}$

\section{TSS for Pediatric Patients}

The recommended management of craniopharyngioma in children remains controversial. ${ }^{9}$ The debate centers around advocacy of radical removal for a surgical cure, $4,11,12,15,18,28,59,65$ radical removal only for the tumors not involving the hypothalamus, , ,19,37,51,53,54 and intentional incomplete tumor removal followed by radiotherapy. ${ }^{26,31}$, $43,45,50,56 \mathrm{In}$ terms of long-term disease control, the results of conservative surgery and radiation therapy for pediatric craniopharyngioma are comparable to the results achieved with radical surgery alone. ${ }^{26,31,43,50,56}$ Based on a review of the literature published from January 1990 to May 2012, including 43 studies with 1716 patients treated with irradiation for craniopharyngioma, Iannalfi et al. reported 10year local control rates of $77 \%-100 \%$ and 20 -year overall survival of $66 \%-92 \%$ for patients undergoing limited surgery and postoperative radiotherapy. ${ }^{26}$ However, radiationinduced side effects are more common in pediatric patients than in adult patients, and the adverse effects from radiation are greater in children younger than 8 years of age and especially concerning in very young patients. ${ }^{45}$ Kiehna and
Merchant state that pediatric patients remain vulnerable to late treatment failure and side effects from radiation therapy, including endocrinopathies, vasculopathies, and secondary tumors, which may be detrimental to QoL. ${ }^{31}$ They concluded that long-term follow-up beyond 5-10 years is necessary to assess tumor control relative to functional outcomes. ${ }^{26}$ In addition, others suggest that radiotherapy may enhance the technical difficulties of subsequent surgery and have an adverse effect on surgical outcomes. ${ }^{18,28}$ To our knowledge, this is the first report describing the outcomes of TSS and exTSS for a large number of pediatric craniopharyngioma patients. Although there have been several reports documenting the use of TSS for resection of craniopharyngiomas in adults, less information is available regarding such treatment in children., $6,17,28,37,55$ Jane et al. speculated that the underrepresentation of the transsphenoidal approach at many children's hospitals is due to the paucity of pediatric pituitary tumors. ${ }^{28}$

We agree with the strategy of near-total resection combined with subsequent radiation as an alternative to GTR when the tumor capsule cannot be separated from vital neurovascular structures and the surgical risks overpower the potential benefit. However, GTR was accomplished in $91 \%$ of patients in this series, with a perioperative mortality of $0 \%$. Our review of previously published case series shows that when GTR was the intended goal of surgery, GTR was achieved in 53\%-70\% of cases (Table 7), highlighting our GTR rate as high. Jane et al. and Elliott et al. reported overall GTR rates of $67 \%$ and $87 \%$, respectively, but in both series, the GTR rate was $100 \%$ when performed as the initial operation. ${ }^{16,28}$ As in these reports, GTR was performed in all but 1 patient (Fig. 3) in our primary surgery cases (GTR rate 98\%), whereas it was performed in $75 \%$ of our repeat surgery cases. We believe this difference is due to the increased adhesion of the tumor to the surrounding vital structures in the repeat surgery cases, probably due to prior surgery and/or radiotherapy.

Indeed, many investigators have reported a strong correlation between a lower recurrence rate and the degree 
of tumor excision, 1,7,13,21,28,33,42 but GTR does not preclude recurrence. Jane et al. reported a $13 \%$ recurrence rate after GTR, compared with a $29 \%$ recurrence rate after a subtotal or partial resection, in their pediatric patients, with a mean follow-up of 82 months. ${ }^{28}$ Consistent with these findings, in our study, at a mean follow-up of 93 months, the tumor recurrence rate was $12 \%$ in the patients in whom GTR was achieved, compared with $50 \%$ in those who underwent STR. In addition, we observed a recurrence rate of only $7 \%$ in primary surgery patients, compared with $27 \%$ in repeat surgery patients $(\mathrm{p}=0.06)$, further supporting the importance of GTR intention in primary surgery. In this series, the 10 patients who had recurrent tumors after GTR via TSS at our institution (3 in the primary surgery group, 7 in the repeat surgery group) and 2 patients who had STR underwent CyberKnife treatment, and they have shown no further disease progression. Radiosurgery is a safe and effective minimally invasive option for the management of small residual or recurrent craniopharyngiomas. ${ }^{27,46}$

\section{Hypothalamus-Sparing Surgery}

Rapid weight gain and severe obesity are considered the most perplexing neuroendocrine complications due to hypothalamic involvement and/or hypothalamic surgical lesions of craniopharyngioma. ${ }^{9}$ Therefore, hypothalamus-sparing surgeries are recommended to prevent severe postoperative neuroendocrine sequelae.,17 Major surgical series have reported a higher mean rate of obesity $(53 \%$, range $32 \%-73 \%), 2,16,39,52,57$ and Müller et al. reported severe obesity in $44 \%$ of children, with a concomitant decrease in QoL. ${ }^{44}$ In contrast, in our series, among the 57 patients without preoperative obesity, new-onset postoperative obesity was found in $4(9 \%)$ of 43 primary surgery patients and $3(21 \%)$ of 14 repeat surgery patients $(\mathrm{p}=0.34)$ despite our aggressive surgery. These frequencies are not higher than those $(28.7 \%$ in males and $21.3 \%$ in females) in the general Japanese population as reported by JPALD (Japan Preventive Association of Life-style related Disease), suggesting that our GTR-intended surgery did not provide significant hypothalamic damage. In contrast, preoperative obesity was significantly higher in repeat than in primary surgery patients $(30 \%$ vs $4 \%, \mathrm{p}<0.01)$, suggesting that prior hypothalamic damage was frequently complicated in repeat surgery patients, which may be due to prior surgery (TCS) and/or radiotherapy. We usually dissect and excise the tumor using a microsurgical technique under direct vision, often excising the tumor sharply from the hypothalamus wall using the reactive gliosis zone between them (as shown in Video 1). Furthermore, with the view from below, it is possible to identify and dissect the walls of the third ventricle, and the dissection plane (or lack thereof) and the hypothalamus can be well visualized to determine the safety of resection without any brain retraction. ${ }^{37}$ It has also been reported that TSS and exTSS are associated with higher GTR rates and lower risks of surgical complications, especially neurological injuries, than TCS. ${ }^{23,29,35}$ During primary surgery, we find a natural cleavage plane between the tumor and the surrounding structures that results from a gliotic reaction. Therefore, in this series, most tumors, even those judged as having hypothalamic involvement based on preoperative MRI (suspected in $38 \%$ in this series), can be totally removed without hypothalamic impairments in almost all primary surgery patients. In contrast, this maneuver is difficult in repeat surgery patients because of severe adhesion of the tumor to the surrounding vital structures after various prior treatments. Thus, the GTR rate was lower in repeat surgery patients, reflecting the effort to prevent or minimize hypothalamic or optic nerve damage from a forcible dissection maneuver.

\section{Visual Outcomes}

Regarding the visual outcomes of TSS in our series, 28 $(62 \%)$ of the patients whose vision was disturbed preoperatively experienced improvement or normalization of their visual disturbance; in 12 patients (27\% of the group with preoperative visual disturbance) there was no change, and in 5 patients $(11 \%)$ the visual disturbance worsened. These data are similar to those described by Jane et al., ${ }^{28}$ who reported that $64 \%$ of pediatric craniopharyngioma patients had improved vision and 14\% experienced visual deterioration; however, other studies have reported no patients showing visual deterioration. 6,10,37,38,55 Similar to observations from other case series, ${ }^{6,57}$ visual improvement was significantly less common (47\% vs $71 \%$ ) and deterioration was more common (24\% vs $4 \%$ ) in repeat surgery patients than in primary surgery patients in our series. Our current data also indicate that the first surgery is quite important for preserving or improving visual function in patients with craniopharyngioma.

\section{Endocrine Outcomes}

Of the 30 patients in the primary surgery group who had normal or only partially disturbed pituitary endocrine function before surgery, 24 (80\%) showed deterioration of endocrine function after surgery. In the repeat surgery group, all 4 patients with normal or only partially disturbed preoperative endocrine function (100\%) showed postoperative deterioration (Table 5). Moreover, new-onset postoperative DI occurred, respectively, in $83 \%$ and $100 \%$ of the primary and repeat surgery patients who did not have DI preoperatively. Previous studies have reported rates of postoperative panhypopituitarism and DI in the ranges of $31 \%-100 \%$ and $33 \%-100 \%$, respectively, following TSS for pediatric craniopharyngiomas, including supradiaphragmatic ones. . $28,37,40,55$ Preservation of the pituitary stalk was attempted during surgery in the patients without preoperative panhypopituitarism and DI, and the stalk morphology was more or less preserved in $46 \%$ (23 of 50 patients). However, in $16(70 \%)$ of these 23 cases the patients developed panhypopituitarism plus DI, indicating that despite the morphological preservation of the pituitary stalk during surgery, the majority of patients still have these sequelae. Our high postoperative endocrinopathy rates may be due to our high GTR rates. In general, children are very vulnerable to recurrence as well as to side effects from radiation therapy, and some authors have advocated that radical resection at presentation offers the best chance of disease control and potential cure with acceptable morbidity in pediatric patients with craniopharyngioma. ${ }^{15}$ Therefore, we remain surgically aggressive in children younger than 8 years old, in whom adverse ef- 
fects from radiation therapy are greatest. ${ }^{45}$ This may also explain the higher incidence of postoperative deterioration of endocrine function. Moreover, when a tumor infiltrates the infundibulum and cannot be fully dissected (Kassam's classification type II), ${ }^{30}$ we prefer to sacrifice the pituitary stalk to achieve radical resection because we cannot guarantee postoperative preservation of pituitary function even after intentional partial resection if we cannot assess the precise location of the stalk in the tumor. One of the benefits of TSS, compared with TCS, for resection of craniopharyngioma is that we can easily identify the anatomical relationship between the stalk and the tumor in the early phase of tumor removal. None of our patients who had hypopituitarism or DI prior to surgery experienced improvement in their pituitary function, similar to what has been found in previous reports. $, 21,30,33,38$ Therefore, it may not be necessary to preserve the pituitary gland and its stalk when pituitary function is completely impaired preoperatively. In fact, 4 (9\%) of 45 patients in the primary surgery group and 15 (75\%) of 20 in the repeat surgery group had preoperative panhypopituitarism and DI. Craniopharyngiomas usually arise from the pituitary stalk, and in patients with stalk infiltration, hypopituitarism and DI are likely to occur when GTR is attempted. In fact, some surgeons contend that the deterioration of pituitary endocrine function after surgery should be accepted as a frequent sequela to attempts at total removal, regardless of the surgical approach. ${ }^{24,35}$ Their rationale is that medication can adequately replace the function of the hypothalamic-pituitary axis; thus, endocrinopathy is a reasonable price to pay for long-term disease remission. However, a recent nationwide population-based study of patients with craniopharyngioma in Sweden demonstrated excess mortality in patients with childhood-onset disease, and hypopituitarism and DI were negative prognostic factors for mortality and morbidity. ${ }^{49}$ Therefore, we must make every effort to spare the pituitary stalk and preserve the pituitary function whenever possible, especially when the patients have intact pituitary function preoperatively. Partial or subtotal removal followed by radiotherapy is an alternative for preserving pituitary function when GTR may put it at significant risk, although there is no consensus in the literature on the acceptable amount of tumor to leave behind in order to preserve pituitary function. In addition, pediatric patients remain vulnerable to late treatment failure and side effects from radiation therapy, including endocrinopathies. ${ }^{31}$ Further study and experience will be needed to clarify whether the recent application of endoscopic technique can improve the chances of total removal and retaining all pituitary functions (pituitary stalk).

\section{Complications}

Postoperative complications, excluding visual deficits, endocrinopathy, and obesity, occurred in $12(18 \%)$ of our 65 patients. Postoperative CSF leaks occurred in $6(9 \%)$, with all 6 of these patients requiring surgery (VP shunt placement in 2 cases) to control CSF leakage. Four of the patients requiring surgery (including the 2 patients treated with VP shunts) were repeat surgery patients. In all cases, the CSF leaks were successfully managed and the incidence of meningitis was low. At present, we rarely use lumbar drainage during or after surgery. Previous studies have shown that CSF leakage is the most frequent postoperative complication following exTSS for craniopharyngioma, and it occurs in $3.8 \%-69 \%$ of patients. ${ }^{21,40}$ Thus, identifying a reliable method to prevent postoperative CSF leakage is a key to success. To reduce postoperative CSF leaks, modified closure techniques have been used, including the septal mucosal flap, multilayer fascia lata, and "gasket seal" methods. ${ }^{21,22,28,32,34,40,61,62}$ Initially, we used autologous fascia grafts, but now we use an autologous fascia graft covered by a vascularized nasoseptal flap, which has significantly reduced the frequency of CSF leakage and reduced the number of suturing knots in the autologous fascia graft. ${ }^{25}$

\section{Conclusions}

Many pediatric craniopharyngiomas have been operated on with TSS at Toranomon Hospital. Our current TSS results for craniopharyngioma resection clearly indicate that GTR can be achieved for most tumors (including ones that were judged as having hypothalamic involvement based on preoperative MRI) without hypothalamic impairment, especially in primary surgery. There were lower GTR rates and higher complication rates in our repeat surgery patients. Based on the results in this series, we believe that GTR should be the goal in pediatric craniopharyngioma surgery via TSS or exTSS when feasible, and it should be achievable without serious complications, although most patients require postoperative hormonal replacement. When GTR is not possible or tumor recurrence occurs after GTR, we recommend radiosurgery to prevent tumor regrowth or progression.

\section{Acknowledgments}

We thank Mrs. Ayako Shitara for her assistance in the preparation of this manuscript.

\section{References}

1. Abe T, Lüdecke DK: Transnasal surgery for infradiaphragmatic craniopharyngiomas in pediatric patients. Neurosurgery 44:957-966, 1999

2. Ahmet A, Blaser S, Stephens D, Guger S, Rutkas JT, Hamilton J: Weight gain in craniopharyngioma-a model for hypothalamic obesity. J Pediatr Endocrinol Metab 19:121-127, 2006

3. Albright AL, Hadjipanayis CG, Lunsford LD, Kondziolka D, Pollack IF, Adelson PD: Individualized treatment of pediatric craniopharyngiomas. Childs Nerv Syst 21:649-654, 2005

4. Bao Y, Qiu B, Qi S, Pan J, Lu Y, Peng J: Influence of previous treatments on repeat surgery for recurrent craniopharyngiomas in children. Childs Nerv Syst 32:485-491, 2016

5. Cappabianca P, Cavallo LM, Esposito F, De Divitiis O, Messina A, De Divitiis E: Extended endoscopic endonasal approach to the midline skull base: the evolving role of transsphenoidal surgery. Adv Tech Stand Neurosurg 33:151-199, 2008

6. Cavallo LM, Frank G, Cappabianca P, Solari D, Mazzatenta D, Villa A, et al: The endoscopic endonasal approach for the management of craniopharyngiomas: a series of 103 patients. J Neurosurg 121:100-113, 2014

7. Chakrabarti I, Amar AP, Couldwell W, Weiss MH: Longterm neurological, visual, and endocrine outcomes following 
transnasal resection of craniopharyngioma. J Neurosurg 102:650-657, 2005

8. Ciric I, Ragin A, Baumgartner C, Pierce D: Complications of transsphenoidal surgery: results of a national survey, review of the literature, and personal experience. Neurosurgery 40:225-237, 1997

9. Daubenbüchel AM, Müller HL: Neuroendocrine disorders in pediatric craniopharyngioma patients. J Clin Med 4:389413, 2015

10. de Divitiis E, Cappabianca P, Cavallo LM, Esposito F, de Divitiis O, Messina A: Extended endoscopic transsphenoidal approach for extrasellar craniopharyngiomas. Neurosurgery 61 (5 Suppl 2):219-228, 2007

11. Dhellemmes P, Vinchon M: Radical resection for craniopharyngiomas in children: surgical technique and clinical results. J Pediatr Endocrinol Metab 19 (Suppl 1):329-335, 2006

12. Di Rocco C, Caldarelli M, Tamburrini G, Massimi L: Surgical management of craniopharyngiomas-experience with a pediatric series. J Pediatr Endocrinol Metab 19 (Suppl 1):355-366, 2006

13. Dusick JR, Esposito F, Kelly DF, Cohan P, DeSalles A, Becker DP, et al: The extended direct endonasal transsphenoidal approach for nonadenomatous suprasellar tumors. J Neurosurg 102:832-841, 2005

14. Dusick JR, Esposito F, Mattozo CA, Chaloner C, McArthur DL, Kelly DF: Endonasal transsphenoidal surgery: the patient's perspective-survey results from 259 patients. Surg Neurol 65:332-342, 2006

15. Elliott RE, Hsieh K, Hochm T, Belitskaya-Levy I, Wisoff J, Wisoff JH: Efficacy and safety of radical resection of primary and recurrent craniopharyngiomas in 86 children. $\mathbf{J}$ Neurosurg Pediatr 5:30-48, 2010

16. Elliott RE, Jane JA Jr, Wisoff JH: Surgical management of craniopharyngiomas in children: meta-analysis and comparison of transcranial and transsphenoidal approaches. Neurosurgery 69:630-643, 2011

17. Elowe-Gruau E, Beltrand J, Brauner R, Pinto G, SamaraBoustani D, Thalassinos C, et al: Childhood craniopharyngioma: hypothalamus-sparing surgery decreases the risk of obesity. J Clin Endocrinol Metab 98:2376-2382, 2013

18. Erşahin Y, Yurtseven T, Ozgiray E, Mutluer S: Craniopharyngiomas in children: Turkey experience. Childs Nerv Syst 21:766-772, 2005

19. Fahlbusch R, Honegger J, Paulus W, Huk W, Buchfelder M: Surgical treatment of craniopharyngiomas: experience with 168 patients. J Neurosurg 90:237-250, 1999

20. Flitsch J, Müller HL, Burkhardt T: Surgical strategies in childhood craniopharyngioma. Front Endocrinol (Lausanne) 2:96, 2011

21. Gardner PA, Kassam AB, Snyderman CH, Carrau RL, Mintz $\mathrm{AH}$, Grahovac S, et al: Outcomes following endoscopic, expanded endonasal resection of suprasellar craniopharyngiomas: a case series. J Neurosurg 109:6-16, 2008

22. Hadad G, Bassagasteguy L, Carrau RL, Mataza JC, Kassam A, Snyderman $\mathrm{CH}$, et al: A novel reconstructive technique after endoscopic expanded endonasal approaches: vascular pedicle nasoseptal flap. Laryngoscope 116:1882-1886, 2006

23. Hofmann BM, Höllig A, Strauss C, Buslei R, Buchfelder M, Fahlbusch R: Results after treatment of craniopharyngiomas: further experiences with 73 patients since 1997. J Neurosurg 116:373-384, 2012

24. Honegger J, Buchfelder M, Fahlbusch R: Surgical treatment of craniopharyngiomas: endocrinological results. J Neurosurg 90:251-257, 1999

25. Horiguchi K, Nishioka H, Fukuhara N, Yamaguchi-Okada $M$, Yamada S: A new multilayer reconstruction using nasal septal flap combined with fascia graft dural suturing for high-flow cerebrospinal fluid leak after endoscopic endonasal surgery. Neurosurg Rev 39:419-427, 2016
26. Iannalfi A, Fragkandrea I, Brock J, Saran F: Radiotherapy in craniopharyngiomas. Clin Oncol (R Coll Radiol) 25:654667,2013

27. Iwata H, Tatewaki K, Inoue M, Yokota N, Baba Y, Nomura R, et al: Single and hypofractionated stereotactic radiotherapy with CyberKnife for craniopharyngioma. J Neurooncol 106:571-577, 2012

28. Jane JA Jr, Prevedello DM, Alden TD, Laws ER Jr: The transsphenoidal resection of pediatric craniopharyngiomas: a case series. J Neurosurg Pediatr 5:49-60, 2010

29. Jeswani S, Nuño M, Wu A, Bonert V, Carmichael JD, Black $\mathrm{KL}$, et al: Comparative analysis of outcomes following craniotomy and expanded endoscopic endonasal transsphenoidal resection of craniopharyngioma and related tumors: a singleinstitution study. J Neurosurg 124:627-638, 2016

30. Kassam AB, Gardner PA, Snyderman CH, Carrau RL, Mintz AH, Prevedello DM: Expanded endonasal approach, a fully endoscopic transnasal approach for the resection of midline suprasellar craniopharyngiomas: a new classification based on the infundibulum. J Neurosurg 108:715-728, 2008

31. Kiehna EN, Merchant TE: Radiation therapy for pediatric craniopharyngioma. Neurosurg Focus 28(4):E10, 2010

32. Kim EH, Ahn JY, Kim SH: Technique and outcome of endoscopy-assisted microscopic extended transsphenoidal surgery for suprasellar craniopharyngiomas. J Neurosurg 114:1338-1349, 2011

33. Kitano M, Taneda M: Extended transsphenoidal surgery for suprasellar craniopharyngiomas: infrachiasmatic radical resection combined with or without a suprachiasmatic translamina terminalis approach. Surg Neurol 71:290-298, 2009

34. Kitano M, Taneda M: Subdural patch graft technique for watertight closure of large dural defects in extended transsphenoidal surgery. Neurosurgery 54:653-661, 2004

35. Komotar RJ, Starke RM, Raper DM, Anand VK, Schwartz TH: Endoscopic endonasal compared with microscopic transsphenoidal and open transcranial resection of craniopharyngiomas. World Neurosurg 77:329-341, 2012

36. Kouri JG, Chen MY, Watson JC, Oldfield EH: Resection of suprasellar tumors by using a modified transsphenoidal approach. Report of four cases. J Neurosurg 92:1028-1035, 2000

37. Koutourousiou M, Gardner PA, Fernandez-Miranda JC, Tyler-Kabara EC, Wang EW, Snyderman CH: Endoscopic endonasal surgery for craniopharyngiomas: surgical outcome in 64 patients. J Neurosurg 119:1194-1207, 2013

38. Laufer I, Anand VK, Schwartz TH: Endoscopic, endonasal extended transsphenoidal, transplanum transtuberculum approach for resection of suprasellar lesions. J Neurosurg 106:400-406, 2007

39. Lek N, Prentice P, Williams RM, Ong KK, Burke GA, Acerini CL: Risk factors for obesity in childhood survivors of suprasellar brain tumours: a retrospective study. Acta Paediatr 99:1522-1526, 2010

40. Leng LZ, Greenfield JP, Souweidane MM, Anand VK, Schwartz TH: Endoscopic, endonasal resection of craniopharyngiomas: analysis of outcome including extent of resection, cerebrospinal fluid leak, return to preoperative productivity, and body mass index. Neurosurgery 70:110-124, 2012

41. Liu JK, Christiano LD, Patel SK, Eloy JA: Surgical nuances for removal of retrochiasmatic craniopharyngioma via the endoscopic endonasal extended transsphenoidal transplanum transtuberculum approach. Neurosurg Focus 30(4):E14, 2011

42. Maira G, Anile C, Albanese A, Cabezas D, Pardi F, Vignati A: The role of transsphenoidal surgery in the treatment of craniopharyngiomas. J Neurosurg 100:445-451, 2004

43. Minniti G, Saran F, Traish D, Soomal R, Sardell S, Gonsalves A, et al: Fractionated stereotactic conformal radiotherapy following conservative surgery in the control of craniopharyngiomas. Radiother Oncol 82:90-95, 2007 
44. Müller HL, Bueb K, Bartels U, Roth C, Harz K, Graf N, et al: Obesity after childhood craniopharyngioma-German multicenter study on pre-operative risk factors and quality of life. Klin Padiatr 213:244-249, 2001

45. Müller HL, Merchant TE, Puget S, Martinez-Barbera JP: New outlook on the diagnosis, treatment and follow-up of childhood-onset craniopharyngioma. Nat Rev Endocrinol 13:299-312, 2017

46. Niranjan A, Kano H, Mathieu D, Kondziolka D, Flickinger JC, Lunsford LD: Radiosurgery for craniopharyngioma. Int J Radiat Oncol Biol Phys 78:64-71, 2010

47. Nishioka H, Fukuhara N, Yamaguchi-Okada M, Yamada S: endoscopic endonasal surgery for purely intrathird ventricle craniopharyngioma. World Neurosurg 91:266-271, 2016

48. Nishioka H, Hara T, Usui M, Fukuhara N, Yamada S: Simultaneous combined supra-infrasellar approach for giant/ large multilobulated pituitary adenomas. World Neurosurg 77:533-539, 2012

49. Olsson DS, Andersson E, Bryngelsson IL, Nilsson AG, Johannsson G: Excess mortality and morbidity in patients with craniopharyngioma, especially in patients with childhood onset: a population-based study in Sweden. J Clin Endocrinol Metab 100:467-474, 2015

50. Pascual J, Freijanes J, Berciano J, Pesquera C: Analgesic effect of octreotide in headache associated with acromegaly is not mediated by opioid mechanisms. Case report. Pain 47:341-344, 1991

51. Pierre-Kahn A, Recassens C, Pinto G, Thalassinos C, Chokron S, Soubervielle JC, et al: Social and psycho-intellectual outcome following radical removal of craniopharyngiomas in childhood. A prospective series. Childs Nerv Syst 21:817824,2005

52. Poretti A, Grotzer MA, Ribi K, Schönle E, Boltshauser E: Outcome of craniopharyngioma in children: long-term complications and quality of life. Dev Med Child Neurol 46:220-229, 2004

53. Puget S, Garnett M, Wray A, Grill J, Habrand JL, Bodaert N, et al: Pediatric craniopharyngiomas: classification and treatment according to the degree of hypothalamic involvement. J Neurosurg 106 (1 Suppl):3-12, 2007

54. Sainte-Rose C, Puget S, Wray A, Zerah M, Grill J, Brauner $\mathrm{R}$, et al: Craniopharyngioma: the pendulum of surgical management. Childs Nerv Syst 21:691-695, 2005

55. Sankhla SK, Jayashankar N, Khan GM: Extended endoscopic endonasal transsphenoidal approach for retrochiasmatic craniopharyngioma: surgical technique and results. J Pediatr Neurosci 10:308-316, 2015

56. Scarzello G, Buzzaccarini MS, Perilongo G, Viscardi E, Faggin R, Carollo C, et al: Acute and late morbidity after limited resection and focal radiation therapy in craniopharyngiomas. J Pediatr Endocrinol Metab 19 (Suppl 1):399-405, 2006

57. Srinivasan S, Ogle GD, Garnett SP, Briody JN, Lee JW, Cowell CT: Features of the metabolic syndrome after childhood craniopharyngioma. J Clin Endocrinol Metab 89:81-86, 2004

58. Steinbok P: Craniopharyngioma in children: long-term outcomes. Neurol Med Chir (Tokyo) 55:722-726, 2015

59. Tomita T, Bowman RM: Craniopharyngiomas in children: surgical experience at Children's Memorial Hospital. Childs Nerv Syst 21:729-746, 2005

60. Weiss M: The transnasal transsphenoidal approach, in Apuzzo MLJ (ed): Surgery of the Third Ventricle. Baltimore: Williams \& Wilkins, 1987, pp 476-494

61. Yamada S, Fukuhara N, Oyama K, Takeshita A, Takeuchi Y, Ito J, et al: Surgical outcome in 90 patients with craniopharyngioma: an evaluation of transsphenoidal surgery. World Neurosurg 74:320-330, 2010

62. Zacharia BE, Amine M, Anand V, Schwartz TH: Endoscopic endonasal management of craniopharyngioma. Otolaryngol Clin North Am 49:201-212, 2016

63. Zada G, Kintz N, Pulido M, Amezcua L: Prevalence of neurobehavioral, social, and emotional dysfunction in patients treated for childhood craniopharyngioma: a systematic literature review. PLoS One 8:e76562, 2013

64. Zada G, Laws ER: Surgical management of craniopharyngiomas in the pediatric population. Horm Res Paediatr 74:62-66, 2010

65. Zuccaro G: Radical resection of craniopharyngioma. Childs Nerv Syst 21:679-690, 2005

\section{Disclosures}

The authors report no conflict of interest concerning the materials or methods used in this study or the findings specified in this paper.

\section{Author Contributions}

Conception and design: Yamada. Acquisition of data: Yamada, Fukuhara, Yamaguchi-Okada, Takeshita, Inoshita, Ito. Analysis and interpretation of data: Yamada, Fukuhara, Yamaguchi-Okada, Inoshita, Ito. Drafting the article: Yamada. Critically revising the article: Fukuhara, Nishioka, Takeshita, Takeuchi, Inoshita, Ito. Reviewed submitted version of manuscript: Yamada, Nishioka, Takeshita, Takeuchi, Ito. Approved the final version of the manuscript on behalf of all authors: Yamada. Statistical analysis: Yamaguchi-Okada. Administrative/technical/material support: Yamada, Inoshita. Study supervision: Yamada, Ito.

\section{Supplemental Information \\ Videos \\ Video 1. https://vimeo.com/251496465.}

\section{Correspondence}

Shozo Yamada: Toranomon Hospital, Tokyo, Japan. syamadays11@hotmail.com. 